\title{
Comparison of novel magnetic polyaluminum chlorides involved coagulation with traditional magnetic seeding coagulation: Coagulant characteristics, treating effects, magnetic sedimentation efficiency and floc properties
}

\author{
Ming Zhang ${ }^{\mathrm{a}, \mathrm{b}}$, Feng Xiao ${ }^{\mathrm{a}, *}$, Dongsheng Wang ${ }^{\mathrm{a}, *}$, Xuzheng $\mathrm{Xu}^{\mathrm{a}}$, Qi Zhou ${ }^{\mathrm{b}}$ \\ a State Key Laboratory of Environmental Aquatic Chemistry, Research Center for Eco-Environmental Sciences, CAS, Beijing 100085, PR China

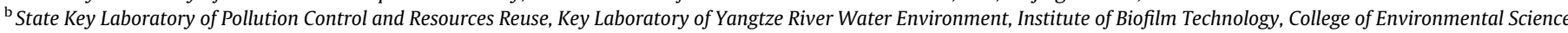 \\ and Engineering, Tongji University, 1239 Siping Road, Shanghai 200092, PR China
}

\section{A R T I C L E I N F O}

\section{Article history:}

Received 19 December 2016

Received in revised form 13 March 2017

Accepted 16 March 2017

Available online 18 March 2017

\section{Keywords:}

Ferromagnetic nanoparticles

Magnetic polyaluminum chloride

Magnetic seeding coagulation

Magnetic sedimentation

Floc property

\begin{abstract}
A B S T R A C T
The present work explored the ferromagnetic nanoparticle-seeded polyaluminum chlorides (PACls), and comparatively investigated their coagulation behaviors and magnetic sedimentation efficiency with the commonly adopted magnetic seeding coagulation. Three magnetic PACls were prepared by dosing ferromagnetic nanoparticles $\mathrm{Fe}_{3} \mathrm{O}_{4}$ or $\mathrm{Fe}(0)$ into the $\mathrm{PACl}$ (basicity 1.5 ) solution. Large clusters of Al speciesmagnetic nanoparticles existed as $\mathrm{Al}_{\text {un }}$ in the magnetic $\mathrm{PACl}$, exhibiting a colloidal surface configuration, according to the results of ${ }^{27} \mathrm{Al}$ nuclear magnetic resonance and atomic force microscope. Compared with seeding magnetic nanoparticles into the treating influent, the magnetic PACls could lead to faster floc sedimentation and lower residual turbidity at equivalent doses of ferromagnetic nanoparticles and $\mathrm{PACl}$; meanwhile, the DOC removal efficiency remained almost at the same level. The flocs produced by the superparamagnetic $\mathrm{Fe}_{3} \mathrm{O}_{4}$-involved PACl were less resistant for breakage and more difficult to re-form than those derived from the traditionally magnetic coagulation. Thus, after breaking the former flocs in the absence of external magnetic field, those separated magnetic seeds can be recovered via replacing the broken flocs in the magnetic field. Importantly, the mass ratio of magnetic powder to coagulant in the magnetic coagulants was reduced from 10,67, 100 or even higher to only 1.5-2.5. In sum, with respect to high magnetic separation efficiency, sound DOC removal, and low magnetic powder demand, the magnetic $\mathrm{PACl}$ with $50 \mathrm{mg} / \mathrm{L} \mathrm{Fe}_{3} \mathrm{O}_{4}$ was considered as the preferable coagulant and the related coagulation-magnetic sedimentation process was more robust than the traditionally magnetic coagulation.
\end{abstract}

(ㄷ) 2017 Published by Elsevier B.V.

\section{Introduction}

To improve the treatment efficiency of coagulationsedimentation, efforts have been dedicated to enhancing the floc formation, reducing the hydraulic retention time, increasing the overflow rate, and decreasing the system footprint $[1,2]$. In this context, the microcarrier-weighted coagulation is developed. Particularly, the ferromagnetic nanoparticle aided process, being named as magnetic coagulation, is growing in popularity at removing either non-magnetic or weakly magnetic matters from water $[3,4]$. The application of magnetic coagulation has been extended to the treatment of drinking water [5], surface water [6,7] and

\footnotetext{
* Corresponding author.

E-mail addresses: fengxiao@rcees.ac.cn (F. Xiao),wgds@rcees.ac.cn (D. Wang).
}

industrial wastewater especially in eliminating turbidity [8], heavy metal ions [9,10], dyes [11] and so forth.

The basic idea of magnetic coagulation-separation is "seeding" the strongly magnetic particles into a fluid suspension where they coagulate with target pollutants; the resulting "seed-pollutant" agglomerates are subsequently removed from the suspension either by sedimentation or filtration in the applied magnetic field [12]. One common way of magnetic seeding is to add magnetic components directly into the target water, and such practice is abundant. This process was used to remove color, turbidity, metals, organic matter and bacteria from waters [13-15]. Wan et al. compared the treating efficiency between two-stage dosing and onestage dosing during the rapid mixing phase, in which magnetic seeds $\left(\mathrm{FeO} * \mathrm{Fe}_{2} \mathrm{O}_{3}\left(\mathrm{Fe}_{3} \mathrm{O}_{4}\right)\right)$ and coagulant were added separately and simultaneously [16]. The former was found to perform better 
than the latter. The leading mechanisms of the magnetic seeding process could be either the electrostatic attraction or the hydrophilic interaction $[17,18]$. Moreover, the magnetic seeding flocculation as well as the magnetic separation units were confirmed to take great advantages in eliminating turbidity and metal ions from surface water and drinking water $[19,20]$.

Another novel and significant approach of magnetic seeding is to prepare magnetic coagulants by combining coagulants with ferromagnetic seeds. In the study of Liu et al. [21,22], the acidly treated chitosan and the fly ash were used to compound with $\mathrm{Fe}_{3} \mathrm{O}_{4}$, respectively, forming magnetic coagulants to treat the algal blooms in a magnetic field. Zhang et al. prepared the magnetic polyaluminum chloride (MPACl) by adding different ferromagnetic nanoparticles into the PACl solutions. The "Al speciesnanoparticle" cluster was proposed to elaborate the unique properties of $\mathrm{MPACl}$ flocs [23]. Additionally, given that the flocs resulted from the complex of ferric salts and polycarboxylic acid are more stable and easier to be removed at the magnetization conditions [24], the iron-based complex may also be considered as magnetic coagulants. Magnetic seeds-involved coagulants take great advantages in improving the water treatment efficiency and effect. Almost 99\% of algal cells could be well removed by magnetic coagulants; meanwhile, residual chemical oxygen demand, total nitrogen, and phosphorus were controlled to a low level $[21,22]$. Seeding ferromagnetic particles in coagulants could obviously reduce the organic pollutants with low and mid-molecular weight as well as the biopolymers with high molecular weight compared with non-magnetic coagulation; therefore, the membrane fouling in the following filtration stage was significantly alleviated [25]. However, to the authors' knowledge, there has been no specific study to compare the performance and potential of these two types of magnetic coagulation-sedimentation.

Humic acid (HA), an important hydrophobic natural organic matter (NOM), has always been regarded as a representative organic pollutant in scientific reports of water treatment [26,27]. HA has a high affinity to magnetic nanoparticles [28-31]: (i) the large specific surface area of nanoparticles offering space for HA adsorption; (ii) the Coulombic interaction between oppositely charged partners of HA and the magnetic surface; (iii) the ligand exchange between HA and the magnetite surface. Accordingly, it is preferable to use magnetic nanoparticles in the HA (or NOM) removal, and thus the magnetic separation could be facilitated.

This study aims at comparing the magnetic coagulant involved coagulation with the traditional magnetic seeding coagulation, and thus determining a promising way of magnetic coagulation. First, $\mathrm{PACl}$ and magnetic PACls were comparatively characterized, and the effects of ferromagnetic nanoaprticles on $\mathrm{PACl}$ properties were explored. Then, the comparison between MPACl-involvedcoagulation (MC) and magnetic seeding coagulation (MSC) were conducted with respect to magnetic sedimentation efficiency, DOC removal, $\xi$-potential variation, and floc properties. The two processes were elaborated from the standpoint of coagulation mechanisms.

\section{Materials and methods}

\subsection{Chemicals}

$\mathrm{FeCl}_{3} \cdot 6 \mathrm{H}_{2} \mathrm{O}, \mathrm{FeCl}_{2} \cdot 4 \mathrm{H}_{2} \mathrm{O}, \mathrm{NaHCO}_{3}$, and absolute ethanol were obtained from National Medicines Corporation Ltd. of China. $\mathrm{NH}_{3}-$ $\cdot \mathrm{H}_{2} \mathrm{O}, \mathrm{NaOH}$ and $\mathrm{HCl}$ were provided by Beijing Chemical Plant. $\mathrm{AlCl}_{3} \cdot 6 \mathrm{H}_{2} \mathrm{O}, \mathrm{NaNO}_{3}$ and Kaolin were provided by Xilong Chemical Corporation Ltd. of Shantou, Jinke Fine Chemical Institute of Tianjin, and Dongxu Chemical Plant of Beijing, China, respectively. Humic acid was produced by Sigma-Aldrich Corporation Ltd. of
USA. All used reagents were analytical grade chemicals. Deionized water with conductivity lower than $0.5 \mathrm{mS} / \mathrm{cm}$ was used to prepare all the solutions and water samples.

\subsection{Synthesis and characterization of magnetic nanoparticles}

Two kinds of magnetic nanoparticles were used in this study: the laboratory-prepared $\mathrm{Fe}_{3} \mathrm{O}_{4}$ (LPF) and the superfine iron powder $\mathrm{Fe}(0)$ (SIP). The synthesis of LPF was based on the study of Hong et al. [32], and the specific procedure has been depicted previously [23]. The LPF product was dried at $-50^{\circ} \mathrm{C}$ under vacuum for $12 \mathrm{~h}$. SIP was offered by the Research Center for Nano Technology of the Chinese Iron and Steel Institute.

The crystalline structures and sizes of LPF and SIP were examined by powder X-ray diffraction (XRD, D/Max-RC, Rigaku, Japan) using $\mathrm{Cu} \mathrm{K} \alpha$ radiation. Vibration sample magnetometer (VSM; Lake Shore 7410), undertaken by the National Institute of Metrology of China, was used for the magnetic hysteresis curves of LPF and SIP in the magnetic field up to $20 \mathrm{kOe}$. The surface charge of magnetic nanoparticles was analyzed with a $\xi$-potential meter (Zetasizer, Malvern, UK), during which the $\mathrm{pH}$ of suspensions was adjusted from 3 to 11 by adding $\mathrm{NaOH}$ or $\mathrm{HCl}$ solutions.

\subsection{Preparation and characterization of PACl and MPACl}

\subsubsection{Preparation}

The synthesis of $\mathrm{PACl}$ was similar to that described by Xu et al. [33], and the molar ratio of $\mathrm{OH} / \mathrm{Al}$ (basicity value) was controlled to 1.5. PACl1.5 was then mixed with LPF or SIP in a shaking table at room temperature $\left(25^{\circ} \mathrm{C}\right)$ for $2 \mathrm{~h}$ at the speed of $250 \mathrm{rpm}$ to prepare MPACls. $\left(\mathrm{PACl}+\mathrm{LPF}_{25} \mathrm{mg} / \mathrm{L}\right) 1.5$ and $\left(\mathrm{PACl}+\mathrm{LPF}_{50 \mathrm{mg} / \mathrm{L}}\right) 1.5$ were prepared by dosing $25 \mathrm{mg} / \mathrm{L}$ and $50 \mathrm{mg} / \mathrm{L}$ LPF into the PACl solution, individually, while $\left(\mathrm{PACl}+\mathrm{SIP}_{100 \mathrm{mg} / \mathrm{L}}\right) 1.5$ was achieved by dosing SIP into PACl at the concentration of $100 \mathrm{mg} / \mathrm{L}$. Those loadings were determined in view of the apparent dispersibility. The final composite MPACl1.5 s were aged $24 \mathrm{~h}$, and conserved at $4{ }^{\circ} \mathrm{C}$. For MC, all the MPACl1.5 s were ultrasonically vibrated for $15 \mathrm{~min}$ before dosing in order to well disperse the composite system.

\subsubsection{Characterization}

2.3.2.1. Liquid ${ }^{27}$ Al nuclear magnetic resonance (NMR). All coagulants were aged for one week, and then Al species of MPACl1.5s and PACl1.5 were measured by $500 \mathrm{MHz}{ }^{27} \mathrm{Al} \mathrm{NMR}$. Instrumental settings and experimental conditions were addressed in the study of $\mathrm{Xu}$ et al. [33]. Mononuclear $\mathrm{Al}\left(\mathrm{Al}_{\mathrm{m}}\right)$ and $\mathrm{Al}_{13}$ were represented by signals near 0 and $62.5 \mathrm{ppm}$, respectively, and their fractions were calculated from the integral intensities of corresponding resonance peaks. $\mathrm{Al}_{\mathrm{un}}$, the amount of undetectable species, was then obtained by:

$\mathrm{Al}_{\mathrm{un}}=\mathrm{Al}_{\mathrm{T}}-\mathrm{Al}_{\mathrm{m}}-\mathrm{Al}_{13}$

2.3.2.2. Atomic force microscopy (AFM). AFM imaging was performed for the structural conformations of PACl1.5 and MPACl1.5s. The used AFM was a NanoScope IIIa Multimode Scanning Probe Microscopy Instrument (Digital Instruments, Santa Barbara, CA) equipped with an E-scanner operating in air at room temperature. The tapping mode AFM was employed to avoid sample destruction. The silicon cantilevers with $125 \mu \mathrm{m}$ in length and $300 \mathrm{kHz}$ in frequency (Nanoprobe, Model RTESP14) were used. The cleaning process of mica plates was the same as that used by Ge et al. [34]. Two mica sheets were prepared and at least three images were obtained for each mica sheet sample. Images were taken with online 
filtering and subsequently by flattening to remove the background slope. Using NanoScope Image analysis software, section analysis of images was conducted for the size estimation.

\subsubsection{Scanning election microscopy and X-ray energy dispersion} (SEM-EDX). The surface morphology and element composition of PACl1.5 before and after being compounded with ferromagnetic nanoparticles was characterized by SEM (LEO1530, Germany) coupled with a EDX detector. The sample was dried by vacuum freezedrying for approximately $48 \mathrm{~h}$ at the vacuum degree of $55 \mathrm{~Pa}$ and the cold trap temperature of $-50^{\circ} \mathrm{C}$, and then sputter coated with gold $(\mathrm{Au})$ before being analyzed at $15 \mathrm{kV}$ accelerating voltage. Principal components were extracted from the X-ray maps using Noran 7 COMPASS software.

\subsection{Water sample}

A synthetic water was prepared at room temperature $\left(16^{\circ} \mathrm{C}\right)$ by dissolving the HA stock solution and kaolin stock suspension in the de-ionized water with $\mathrm{NaHCO}_{3}$ to provide ionic strength and $\mathrm{pH}$ buffer. In the synthetic water, average values of $\xi$-potential, turbidity, DOC, ionic strength and alkalinity were measured to be $-54.4 \mathrm{mV}, 79.5 \mathrm{NTU}, 0.264 \mathrm{~cm}^{-1}, 2.239 \mathrm{mg} / \mathrm{L}, 1.0 \mathrm{mmol} / \mathrm{L}$ and $80 \mathrm{mg} / \mathrm{L}$, respectively.

\subsection{Coagulation and magnetic separation}

Firstly, in the absence of external magnetic field, a series of jar tests were performed in a dosage range of $0.02-0.20 \mathrm{mmol} / \mathrm{L}$ as $\mathrm{Al}$ and an initial water $\mathrm{pH}$ range of $4-11$. The related procedure and apparatus of jar tests can be referred to the former publication [23]. Thus, the $\mathrm{PACl}$ and $\mathrm{MPACl}$ dosages and initial $\mathrm{pH}$ condition were predetermined for the subsequent coagulation-magnetic separation trials. MC and MSC were then compared: after jar tests, all coagulated suspensions were immediately transferred to an external magnetic field of $2 \mathrm{~T}$ for sedimentation, and the turbidity of supernatant was measured at $5 \mathrm{~min}$ interval during the magnetically settling period by turbidimeter (Hach 2100P Turbidimeter, USA). The strong magnetic field was generated by a multi-pole permanent magnet (DLSM-II-4.0, Dawning Environmental Science and Technology Co., Ltd., China). It should be noted that, for MSC, aqueous suspensions of ferromagnetic nanoparticles were prepared by dispersing approximately $10 \mathrm{mg}$ LPF or SIP nanoparticles into $100 \mathrm{~mL}$ de-ionized water and ultrasonically vibrating the mixture for $2 \mathrm{~h}$. Those suspensions were conserved at $4{ }^{\circ} \mathrm{C}$ and used up in 2 days. In the jar test process, they were ultrasonically vibrated again for $15 \mathrm{~min}$ for the uniform dispersion before dosing. The MSC was carried out by simultaneously dosing PACl1.5 and the dispersion of ferromagnetic nanoparticles. Equivalent dosages of PACl1.5 and ferromagnetic nanoparticles were applied as in the MC tests.

A small amount of sample was taken immediately to measure the $\xi$-potential (Malvern, Zetasizer 2000, UK) after $30 \mathrm{~s}$ rapid mix in the coagulation stage. The sample of the supernatant water was taken for water quality analyses after the final sedimentation step (30 min). DOC of the supernatant was analyzed by a TOC analyzer (TOC-Vcph, Shimadzu, Japan) after filtration through $0.45 \mu \mathrm{m}$ membrane, and $\mathrm{pH}$ values were measured using a $\mathrm{pH}$ meter (MP220, Mettler-Toledo, Switzerland).

\subsection{Floc property}

\subsubsection{Floc formation, breakage and regrowth}

A particle size analyzer (Mastersizer 2000, Malvern Corp., UK) with a small angle static light scattering was used to directly monitor dynamics of the floc growth-breakage-regrowth process.
Details of the procedure can be found in the earlier publication [23]. Coagulation tests were carried out at the optimum coagulant dosage. Flocs formed by MC and MSC (viewed as "MC-flocs" and "MSC-flocs", respectively) were compared from aspects of particle size, growth rate, strength factor and recovery factor. The strength factor $\left(S_{f}\right)$ and recovery factor $\left(R_{f}\right)$ can be calculated as follows:

$S_{f}=\frac{d_{2}}{d_{1}} \times 100 \%$

$R_{f}=\frac{d_{3}-d_{2}}{d_{1}-d_{2}} \times 100 \%$

where $d_{1}$ is the average floc size of the steady region, $d_{2}$ is the floc size after breakage, and $d_{3}$ is the average floc size of the re-steady phase.

\subsubsection{Fractal dimension $\left(D_{f}\right)$}

The fractal structure of flocs was investigated, and a higher $D_{f}$ value corresponds to a more compact interior floc structure [35]. Light scattering experiment is an important tool for its determination. The detailed principle and method has been presented by Jarvis et al. [36]. The light scattering technique involves measurement of light intensity $I$ as a function of the scattering wave vector $Q$, where $Q$ is the difference between the incident and scattered wave vectors of the radiation beam in the medium. For independently scattering aggregates, the log-log plot of $I$ against $Q$ from data collected in scattering tests is linear, with a slope of $D_{f}$ :

$I \propto Q^{-D_{f}}$

where the parameter $D_{f}$ is the mass fractal dimension of the aggregates, ranging from 1 to 3 for physically relevant objects. A higher $D_{f}$ value corresponds to a more compact interior floc structure [35].

\section{Results and discussion}

\subsection{Properties of ferromagnetic nanoparticles}

The diffraction characteristic peaks of LPF indicated its highly crystalline inverse cubic spinel phase; those of SIP corresponded to the diffraction planes of $\alpha$-Fe (Fig. S1). Crystallite sizes of the LPF and SIP were calculated to be $11.2 \mathrm{~nm}$ and $9.3 \mathrm{~nm}$ according to the Scherrer's equation [37]. It is generally accepted that the $\mathrm{Fe}_{3} \mathrm{O}_{4}$ and $\alpha$-Fe particles turn to be superparamagnetic when their particle sizes are smaller than $16 \mathrm{~nm}$ and $5 \mathrm{~nm}$, respectively [38]. Therefore, the LPF is qualified to be the superparamagnetic nanoparticle whereas the SIP should be of paramagnetism. The weak remanence effect of LPF (Fig. S2) confirmed that the LPF could show the superparamagnetic behaviors in an external magnetic field. For superparamagnetic materials, their thermal energy is able to overcome the anisotropy energy barrier of a single particle, and the net magnetization of particle assemblies in the absence of an external field is zero [39]. This property meets well with the requirement of magnetically assisted chemical separation [40]. Once the external magnetic field is removed after the magnetic sedimentation, no magnetic attraction exists between particles anymore; thus, the superparamagnetic particles may be more easily separated from the collected sludge through breaking the flocs; thereafter, magnetic particles can be recovered by replacing them in the magnetic field. Additionally, as shown in Fig. S3 the isoelectric point (IEP) of LPF was measured to be at approximately pH 6.4 while that of SIP was at around pH 6.6. 
Table 1

Species distribution and $\xi$-potential of MPACl1.5 and PACl1.5.

\begin{tabular}{|c|c|c|c|c|}
\hline & PACl1.5 & $\left(\mathrm{PACl}+\mathrm{LPF}_{25 \mathrm{mg} / \mathrm{L}}\right) 1.5$ & $\left(\mathrm{PACl}+\mathrm{LPF}_{50 \mathrm{mg} / \mathrm{L}}\right) 1.5$ & $\left(\mathrm{PACl}+\mathrm{SIP}_{100 \mathrm{mg} / \mathrm{L}}\right) 1.5$ \\
\hline $\mathrm{Al}_{\text {un }}(\%)$ & 30.3 & 30.4 & 32.8 & 37.7 \\
\hline $\mathrm{Al}_{13}(\%)$ & 40.6 & 39.0 & 39.0 & 35.8 \\
\hline $\mathrm{Al}_{\mathrm{m}}(\%)$ & 29.1 & 30.6 & 28.2 & 26.5 \\
\hline$\xi$-potential $(\mathrm{mV})$ & +2.5 & +22.5 & +28.6 & +17.4 \\
\hline
\end{tabular}
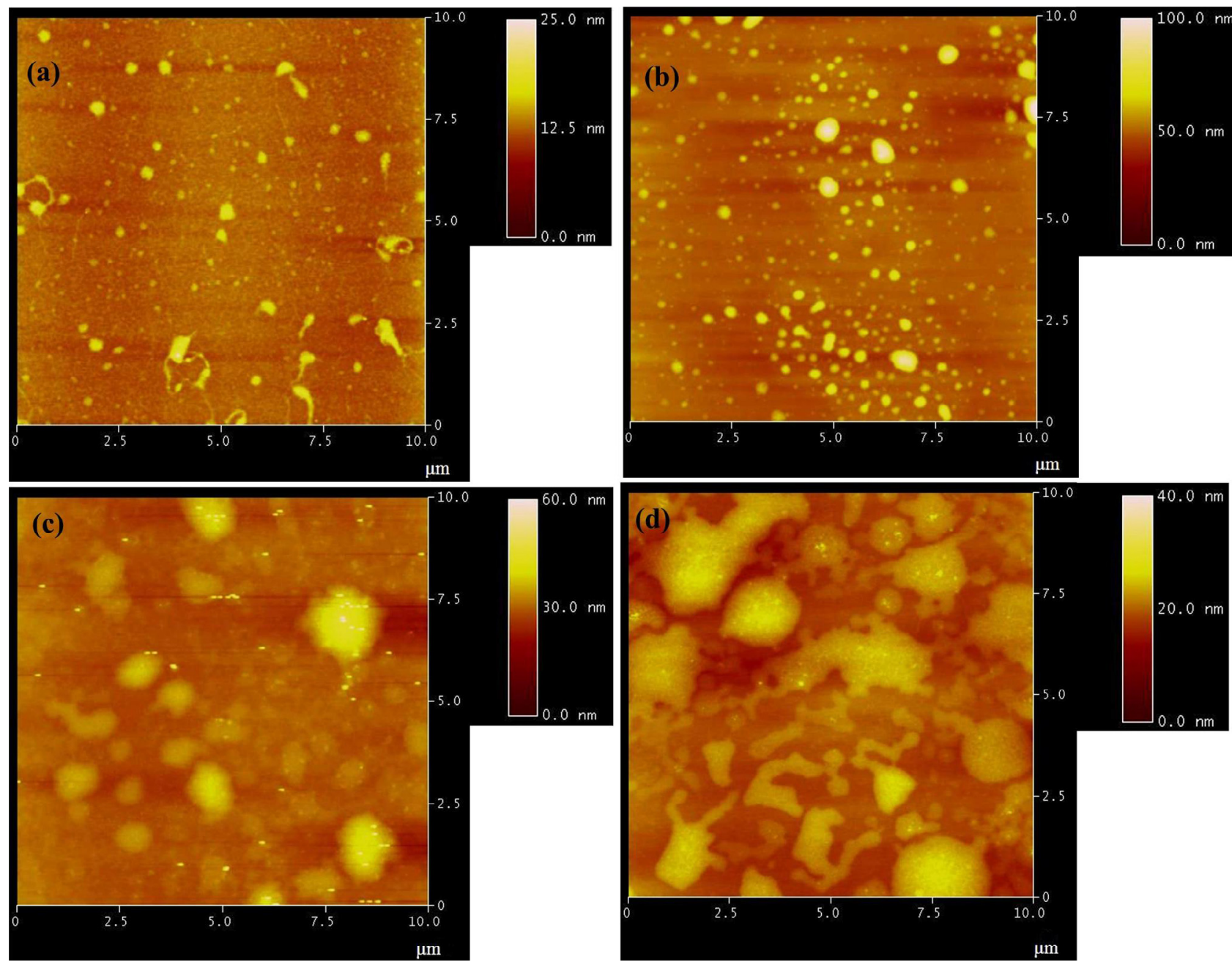

Fig. 1. AFM images of coagulants: (a) $\mathrm{PACl} 1.5$, (b) $\left(\mathrm{PACl}+\mathrm{LPF}_{25} \mathrm{mg} / \mathrm{L}\right) 1.5$, (c) $\left(\mathrm{PACl}+\mathrm{LPF}_{50 \mathrm{mg} / \mathrm{L}}\right) 1.5$, (d) $(\mathrm{PACl}+\mathrm{SIP} 100 \mathrm{mg} / \mathrm{L}) 1.5$.

\subsection{Characteristics of magnetic coagulants}

\subsubsection{Al species distribution and surface charge characterization}

An increasing loading of magnetic nanoparticles resulted in the change of $\mathrm{Al}$ species distribution in coagulant (Table 1). The concentration of undetectable $\mathrm{Al}$ species rose whereas that of $\mathrm{Al}_{13}$, Al-monomer and Al-oligomer declined. Especially for PACl1.5 composited with the SIP at $100 \mathrm{mg} / \mathrm{L}$, the $\mathrm{Al}_{\mathrm{un}}$ content reduced to $37.7 \%$ while the $\mathrm{Al}_{13}$ and $\mathrm{Al}_{\mathrm{m}}$ went up to $35.8 \%$ and $26.5 \%$, respectively.

It is noteworthy that even a trace amount of magnetic nanoparticles (no more than $100 \mathrm{mg} / \mathrm{L}$ ) could facilitate the formation of larger polymer such as the solid-phase $\mathrm{Al}_{\text {un }}$ or $\mathrm{Al}(\mathrm{OH})_{3}$. The large specific surface area, the inadequate coordination of surface atoms, and the strong adsorptive capacity of nano-scaled LPF and SIP might be the reasonable explanation for the aggregation in the MPACl1.5 solid-liquid system. As discussed previously [23], $\mathrm{Al}_{\mathrm{m}}$ and $\mathrm{Al}_{13}$ possibly went through $\left[\mathrm{Al}_{\mathrm{m}}\right] \rightarrow\left[\mathrm{Al}_{\mathrm{m}}\right]_{\mathrm{n}} \rightarrow\left[\mathrm{Al}_{\mathrm{un}}\right]$ and $\left[\mathrm{Al}_{13}\right] \rightarrow\left[\mathrm{Al}_{13}\right]_{\mathrm{n}} \rightarrow\left[\mathrm{Al}_{\mathrm{un}}\right]$ in the compositing and aging process of $\mathrm{MPACl}$. Here, $\left[\mathrm{Al}_{\mathrm{un}}\right]$ was the aggregate of $\mathrm{Al}$ species and nanoparticles (presented as "Al species-nanoparticle cluster" in our study). The aggregates were of great potential in adsorbing-bridging, sweeping and enmeshing flocculation capacity. The $\xi$-potential of PACl1.5 were close to zero, indicating the $\mathrm{Al}$ species $\left(\mathrm{Al}_{\mathrm{m}}, \mathrm{Al}_{13}\right.$ and $\mathrm{Al}_{\text {un }}$ ) existing in the soluble form, while that of MPACls became positive, implying the adhesion of Al species on the ferromagnetic surface.

3.2.2. Morphological observation, size evaluation and element analysis

AFM was used to observe the morphological changes of PACl1.5 compounded with ferromagnetic nanoparticles LPF and SIP. A spotlike photograph of PACl1.5 was found in Fig. 1(a), and there were two populations in width: smaller than $0.1 \mu \mathrm{m}$ and $0.3-0.5 \mu \mathrm{m}$. 

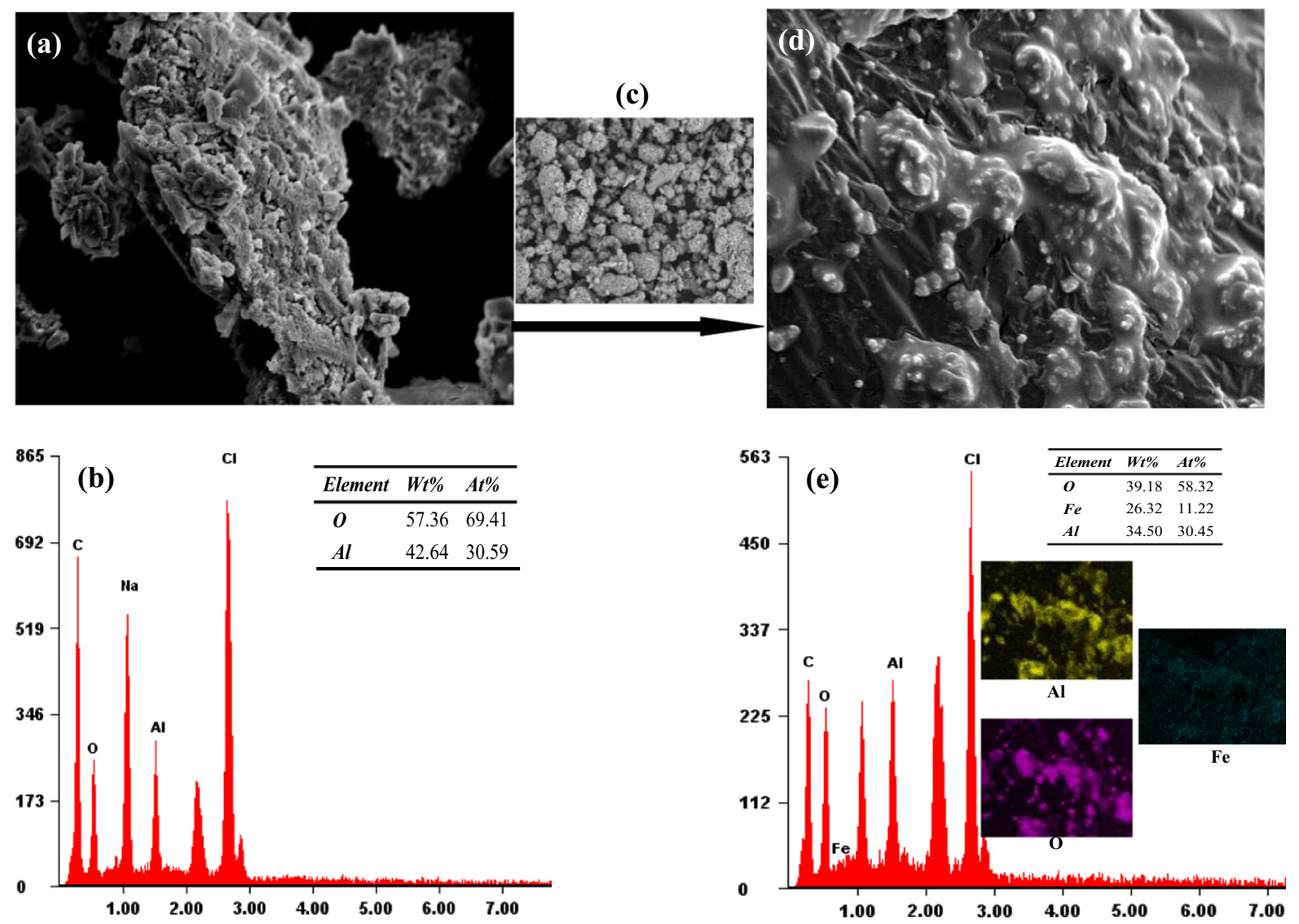

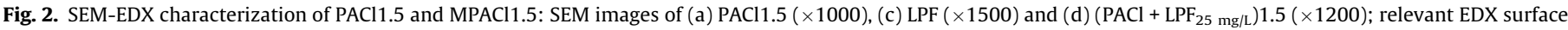
analysis of (b) PACl1.5 and (e) $\left(\mathrm{PACl}+\mathrm{LPF}_{25} \mathrm{mg} / \mathrm{L}\right) 1.5$.

On adding ferromagnetic nanoparticles, morphologies of MPACl1.5 s by AFM went different: the MPACl1.5 with $25 \mathrm{mg} / \mathrm{L}$ LPF was found to be sphere-like with $0.3-0.6 \mu \mathrm{m}$ in width (Fig. 1 (b)); at higher LPF concentration of $50 \mathrm{mg} / \mathrm{L}$, larger aggregates with $0.8-2 \mu \mathrm{m}$ in width appeared (Fig. 1(c)); the (PACl + SIP $100 \mathrm{mg} / \mathrm{L}) 1.5$ exhibited multiple assembly structures with the largest size among investigated coagulants, including aggregates of sphere, branch-like structure and perforated sheets (Fig. 1(d)). Conformations and sizes of PACl1.5 and MPACl1.5 derived from AFM further confirmed the ${ }^{27} \mathrm{Al} \mathrm{NMR}$ analysis of Al species. It can be inferred that $\mathrm{Al}$ species congregated on ferromagnetic nanoparticles, forming "Al species-nanoparticle cluster" $\left(\mathrm{Al}_{\mathrm{un}}\right)$. The more amount of magnetic nanoparticles were added, the larger $\mathrm{Al}_{\text {un }}$ could be achieved, leading to the conformation from small spots, large spheres to even larger aggregates.

The morphology of $\mathrm{PACl}$ before and after being mixed with ferromagnetic nanoparticles is related to the surface composition. Herein, SEM micrographs and EDX analysis of PACl1.5 and (PACl $\left.+\mathrm{LPF}_{25 \mathrm{mg} / \mathrm{L}}\right) 1.5$ are presented in Fig. 2 as representative of coagulants in this study. The inner structure of PACl1.5 was porous and irregular, containing several typical $\mathrm{Al}_{13}$ crystals (Fig. 2(a)); by adding LPF particles (Fig. 2(c)), the surface of MPACl1.5 turned to be compact with colloidal aggregates (Fig. 2(b)). The marked change could be attributed to the aggregation of $\mathrm{Al}_{\mathrm{m}}$ and $\mathrm{Al}_{13}$ on the LPF surface. Those $\mathrm{Al}_{\mathrm{m}}$ and $\mathrm{Al}_{13}$ aggregates assembled particles by interparticle bridging, led to the formation of $\mathrm{Al}_{\mathrm{un}}$, and meanwhile gave rise to the colloidal configuration of $\mathrm{MPACl}$. The element analysis and distribution images in Fig. 2(b) clearly demonstrated that blue spots (Fe) spread over the surface of MPACl sample we observed, revealing that magnetic particles had been well compounded with the MPACl coagulant.

\subsection{Determination of coagulation conditions in the absence of external magnetic field}

Preliminary coagulation tests were carried out to optimize the coagulant dosage and coagulation $\mathrm{pH}$ condition (Figs. 3and 4). Initially, the $\mathrm{pH}$ value of the synthetic water was fixed at $7.60 \pm 0.02$ for the optimization of coagulant dosage. Residual DOC after coagulation decreased as the increase of coagulant dosage (Fig. 3(a)), and meanwhile the $\xi$-potential kept rising from negative to positive. The MPACl1.5 had a better organic matter removal at the dosage lower than $0.04 \mathrm{mmol} / \mathrm{L}$ as $\mathrm{Al}$. The optimum dosage for organic matter removal (DOC removal) is $0.08 \mathrm{mmol} / \mathrm{L}$ as $\mathrm{Al}$ for both MPACl1.5 s and PACl1.5. Thereafter, results of $\mathrm{pH}$ optimization tests showed that the coagulation performance began to deteriorate when the initial $\mathrm{pH}$ was higher than 7.5. At $\mathrm{pH}$ of synthetic water higher than 10, MPACl1.5s exhibited a stronger DOC removal capacity than PACl as shown in Fig. 4(a). The optimum coagulation condition for the DOC removal was determined as $0.08 \mathrm{mmol} / \mathrm{L}$ as $\mathrm{Al}$ for coagulant dosage and $\mathrm{pH} 7.00 \pm 0.02$ for the synthetic water, under which magnetic separation behaviors of MC and MSC from the aspect of residual turbidity in an external magnetic field were compared and discussed in following sections.

\subsection{Coagulation-magnetic separation performance in the presence of external magnetic field}

The residual turbidity of MC and MSC along with the settling time was comparatively shown in Fig. 5. It is evident that the final turbidity of both MC and MSC was lower than that of the coagulation without magnetic particles. MC yielded better turbidity removal efficiency than MSC for an equivalent ferromagnetic 

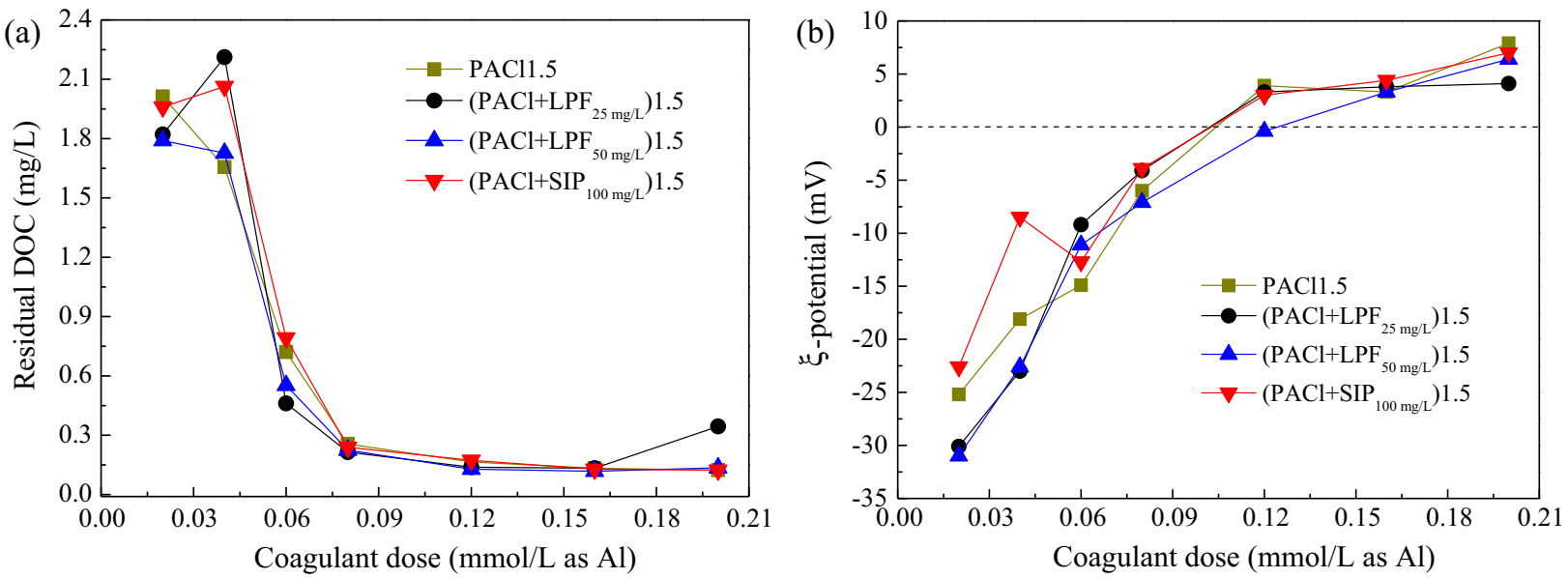

Fig. 3. Coagulation performance varying with PACl1.5 and MPACl1.5 dosage: (a) residual DOC and (b) $\xi$-potential.
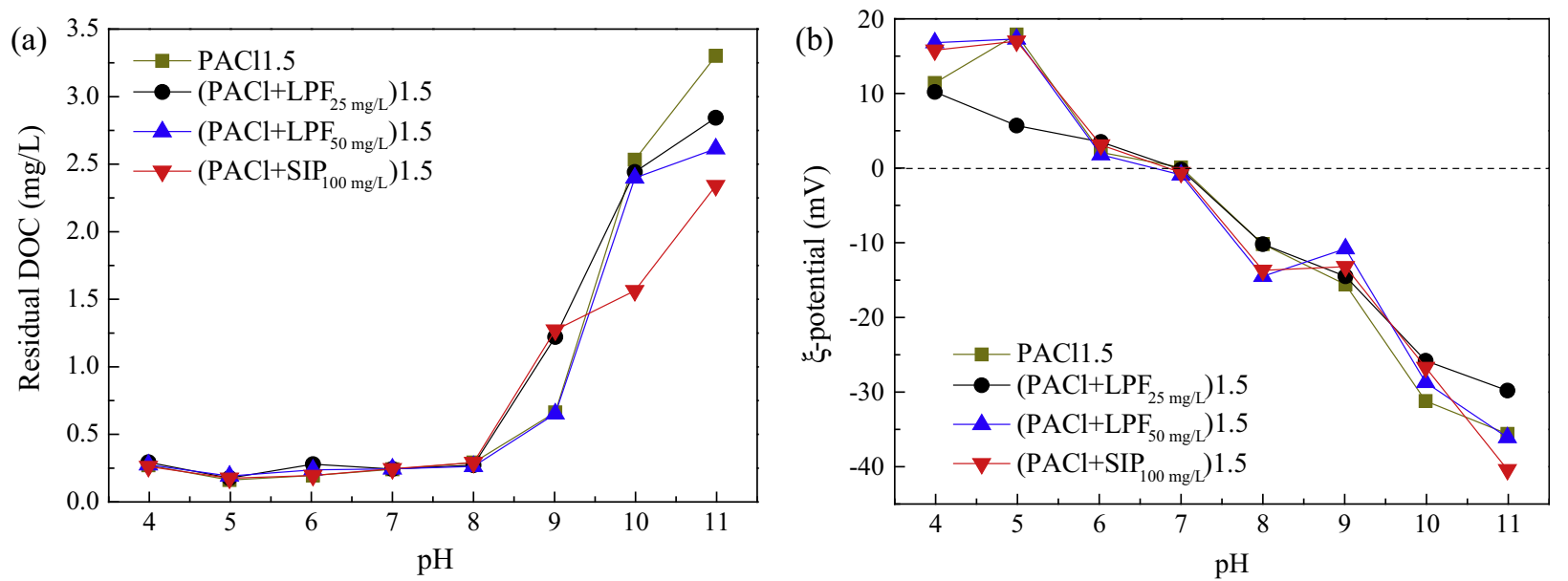

Fig. 4. Coagulation performance varying with $\mathrm{pH}$ value of synthetic water: (a) residual DOC and (b) $\xi$-potential.

nanoparticle dosage in a given magnetic field. For the LPF-involved magnetic coagulation-separation process, the higher LPF addition ( $50 \mathrm{mg} / \mathrm{L}$ ) could give rise to lower residual turbidity for both MC and MSC. As for SIP, the difference between MC and MSC was smaller even though the highest addition of $100 \mathrm{mg} / \mathrm{L}$ SIP was used; the residual turbidity remained around $10 \mathrm{NTU}$, higher than that of LPF-involved processes. Hence, the preferable magnetic coagulation condition should be $\mathrm{MC}$ of $\left(\mathrm{PACl}+\mathrm{LPF}_{50} \mathrm{mg} / \mathrm{L}\right) 1.5$ with respect to higher turbidity removal efficiency.

In the MSC, when being added into the synthetic water, those ferromagnetic nanoparticles would be negatively surface-charged (approximately $-5.5 \mathrm{mV}$ for LPF and $-3.1 \mathrm{mV}$ for SIP, according to Fig. S3) since the aquatic $\mathrm{pH}$ value was around 7.00. Thus, the highly positively charged PACl was more likely to interact with the negatively surface-charge kaolin particles by electrostatic attraction and binding affinity, forming flocs. As the $\xi$-potential of coagulated particles approached to zero and further reversed to be positive, the magnetic nanoparticles were apt to adsorb on coagulated flocs via the large specific surface area and high density of reactive surface. Additionally, the PACl that surrounded kaolin particles would separate magnetic seeds and kaolin particles, and reduce the opportunity of collision between kaolin particles and magnetic seeds [16].

In contrast, in the MC process, MPACls had been well combined with magnetic nanoparticles and $\mathrm{Al}$ species-magnetic nanoparticle clusters (considered as $\mathrm{Al}_{\mathrm{un}}$ ) were preformed. On dosing into the synthetic water and mixed with kaolin particles, more magnetic nanoparticles could participate in the formation of flocs. Therefore, compared with MSC-flocs, the magnetic flocs formed by MC had greater potential of magnetic separation in an external magnetic field. Moreover, according to Fig. S3, the surface charge of LPF and SIP in MPACl should be positive since the pH of PACl1.5 was in the acidic range (lower than 4). Those positively charged nanoparticles could preferably agglomerate with the negatively charge contaminants, leading to the higher sedimentation efficiency of MC [4].

The comparison of MC and MSC in terms of DOC removal, $\xi$ potential and $\mathrm{pH}$ is presented in Fig. 6. The organic matter removal has been reduced from $2.239 \mathrm{mg} / \mathrm{L}$ to a quite low level (around $0.18 \mathrm{mg} / \mathrm{L}$ ) by the non-magnetic coagulation-separation process. The residual DOC and $\mathrm{pH}$ value after MC and MSC did not make great difference under the optimum coagulating condition. It demonstrated that the trace amount of ferromagnetic nanoparticles in this study endowed the coagulated flocs a stronger sedimentation capacity by magnetic separation on the premise of keeping its capacity of eliminating the organic matter. The $\xi$ potential of coagulating systems by MC and MSC was slightly higher than that of the non-magnetic coagulation, confirming that the addition of ferromagnetic nanoparticles enhanced the attractive force between positively charged $\mathrm{PACl}$ and negatively surface 


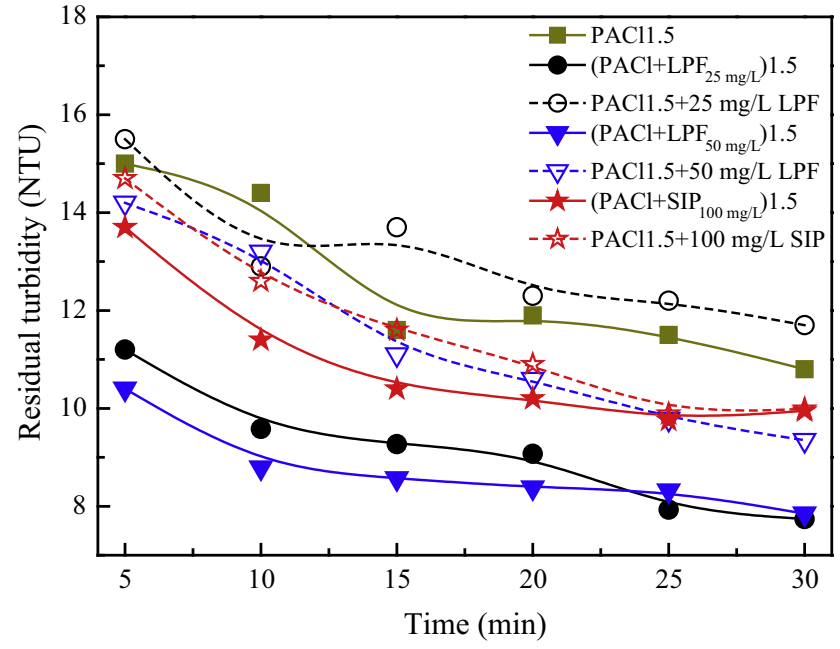

Fig. 5. Residual turbidity as a function of settling time at the predetermined coagulation condition.

charged kaolin particles. On the account of the coagulation performance and the magnetic separation efficiency, MC with (PACl + LPF)1.5 is preferred in the magnetic coagulation-separation treatment.

\subsection{Comparison between MC-flocs and MSC-flocs}

When coagulating the synthetic water of HA and kaolin particles at a fixed coagulant dosage of $0.08 \mathrm{mmol} / \mathrm{L}$ as $\mathrm{Al}$ in $\mathrm{MC}$ and MSC processes, different floc growth-breakage-regrowth profiles were obtained, as presented by the median equivalent volumetric diameter $\left(d_{50}\right)$ in Fig. 7. Floc properties including size, strength factor, recovery factor, and fractal dimension are summarized in Table 2.

In the growth period, both MC-flocs and MSC-flocs quickly reached their greatest size at the given shear rate. Coagulating suspensions stayed a rather short balance and then experienced a reduction of floc size, except the coagulation with (PACl $\left.+\mathrm{LPF}_{25 \mathrm{mg} / \mathrm{L}}\right) 1.5$ and $\left(\mathrm{PACl}+\mathrm{SIP}_{100 \mathrm{mg} / \mathrm{L}}\right) 1.5$ which kept the comparatively steady state in size. A general tendency illustrated that MC gave rise to smaller flocs. Subsequently, the floc breakage within the 1 min caused sharp drops of floc size to the same level (44$69 \mu \mathrm{m})$ in all coagulating suspensions. When the stirring speed

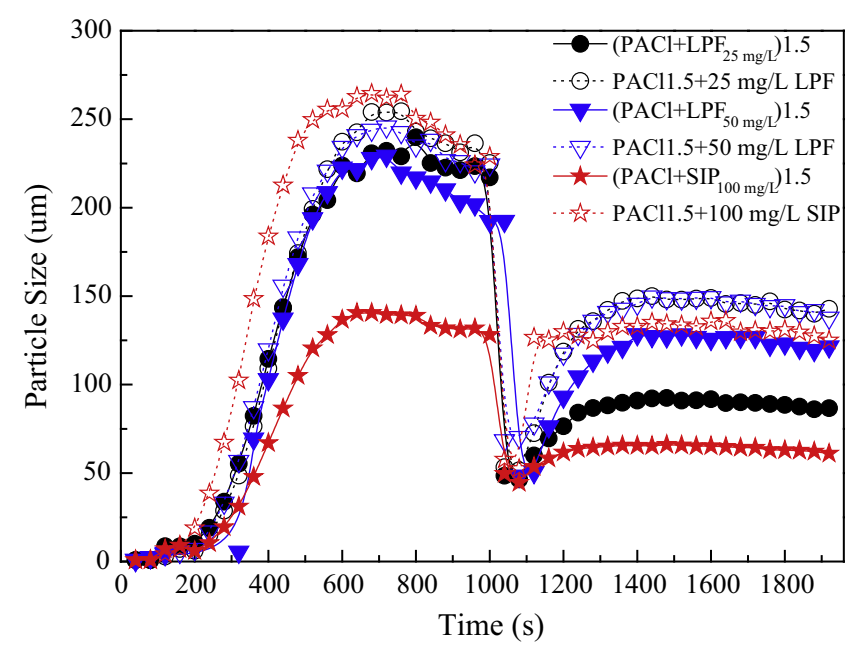

Fig. 7. Growth-breakage-regrowth files of flocs formed by MC and MSC.

turned back to $40 \mathrm{rpm}$, a reversibility phenomenon with regard to the floc size was observed, and MSC-flocs regrew to larger sizes in shorter time compared with MC-flocs. The regrowth plateau was always lower than that in the growth period indicating that the breakage of alum flocs under the stated conditions is not completely reversible [41].

It is apparent in Table 2 that LPF-involved MC promoted more compact flocs with lower strength factor than LPF-involved MSC. It has been well known that the floc strength is closely related to the particle bond strength and the number of interparticle bonds [42]. As interpreted in Section 3.2, compared with PACl, the increase of $\mathrm{Al}_{\mathrm{un}}$ and the decrease of $\mathrm{Al}_{13}$ and $\mathrm{Al}_{\mathrm{m}}$ in MPACls would strengthen their ability of bridging, sweeping and enmeshing pollutants, but somehow weaken the electrostatic attraction between $\mathrm{MPACl}$ and negatively charge surfaces. Thereby, the (PACl + LPF) 1.5-induced flocs were less shear-resistant than the (PACl1.5 + LPF)-induced. Compared with MSC with $100 \mathrm{mg} / \mathrm{L}$ SIP, stronger flocs were formed in the $\left(\mathrm{PACl}+\mathrm{SIP}_{100 \mathrm{mg} / \mathrm{L}}\right) 1.5$-involved MC. It may be attributed to the fact that the over-added magnetic nanoparticles (i.e. $100 \mathrm{mg} / \mathrm{L}$ in this study) was likely to aggregate themselves via the magnetic attraction, forming the shear-resist flocs.

For the MC-flocs, when exposing at high share rates, the Al species-magnetic nanoparticle clusters may be broken, and the
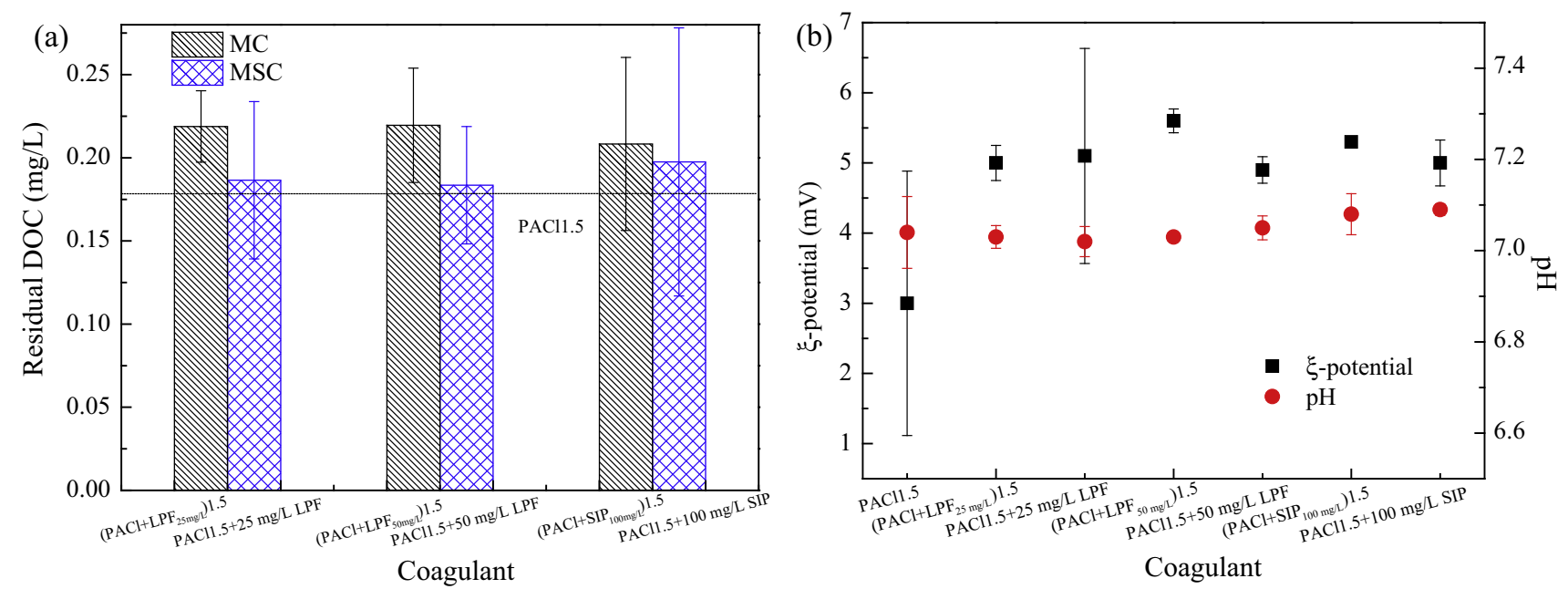

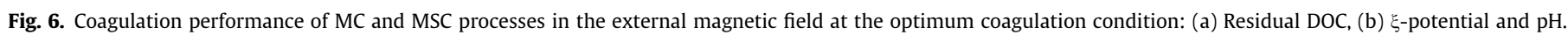


(a)

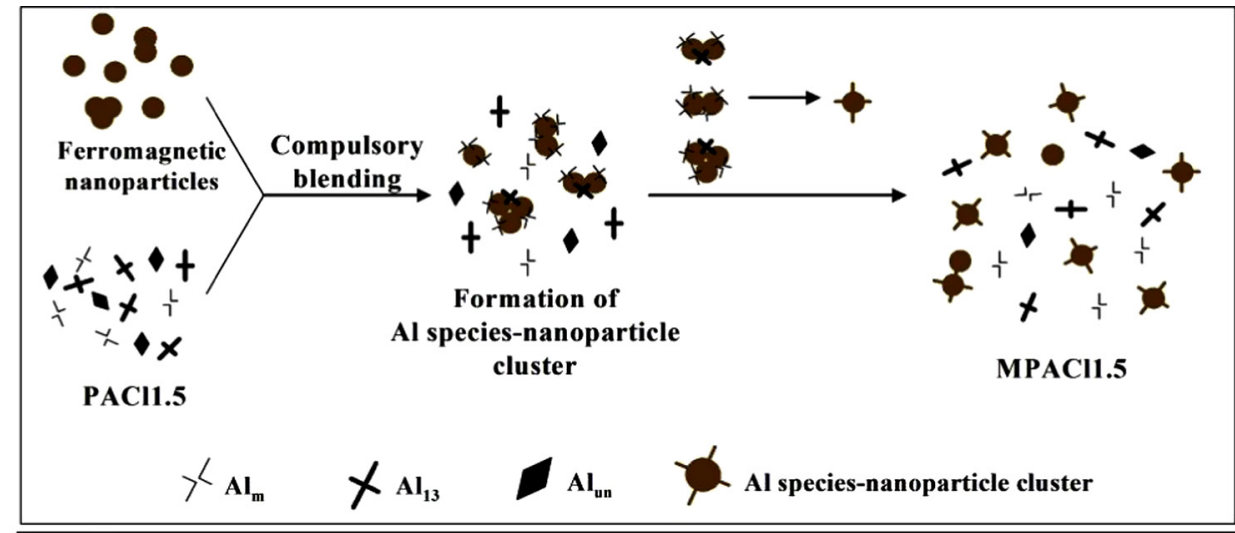

(b)
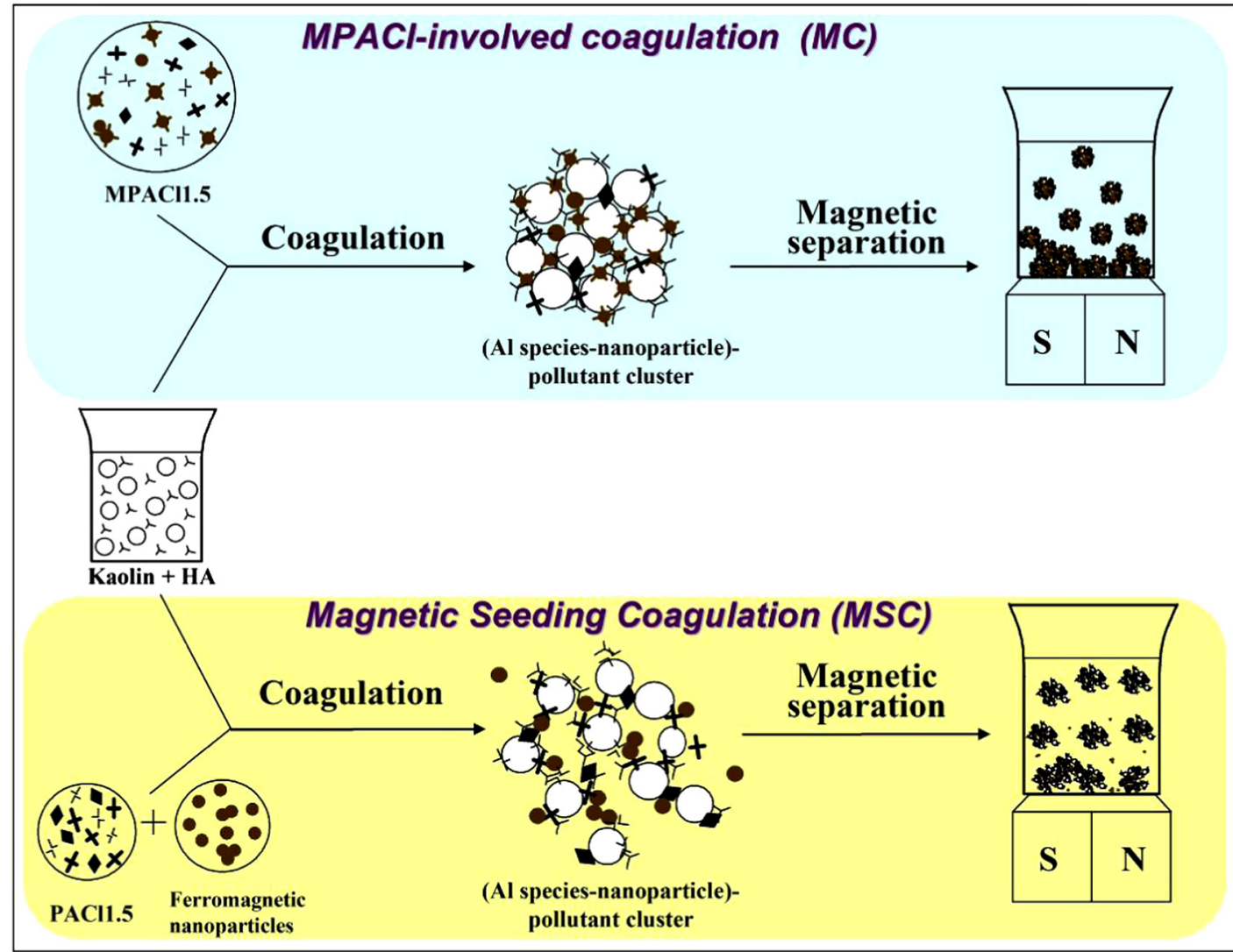

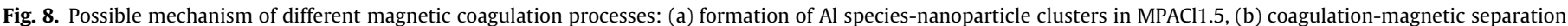
processes of MC and MSC.

Table 2

Size, strength and recovery factor, fractal dimension of flocs formed by MC and MSC.

\begin{tabular}{|c|c|c|c|c|c|c|c|c|}
\hline & \multirow[t]{2}{*}{$\mathrm{d}_{1}(\mu \mathrm{m})$} & \multirow[t]{2}{*}{$\mathrm{d}_{2}(\mu \mathrm{m})$} & \multirow[t]{2}{*}{$\mathrm{d}_{3}(\mu \mathrm{m})$} & \multirow[t]{2}{*}{ Strength factor $S_{f}(\%)$} & \multirow[t]{2}{*}{ Recovery factor $R_{f}(\%)$} & \multicolumn{3}{|c|}{ Fractal dimension $D_{f}$} \\
\hline & & & & & & Growth & Breakage & Regrowth \\
\hline$\left(\mathrm{PACl}+\mathrm{LPF}_{25} \mathrm{mg} / \mathrm{L}\right) 1.5$ & 225.9 & 46.4 & 89.2 & 20.5 & 23.8 & 2.67 & 2.89 & 2.76 \\
\hline PACl $1.5+25 \mathrm{mg} / \mathrm{L}$ LPF & 239.6 & 51.5 & 145.8 & 21.5 & 50.1 & 2.64 & 2.85 & 2.72 \\
\hline$\left(\mathrm{PACl}+\mathrm{LPF}_{50 \mathrm{mg} / \mathrm{L}}\right) 1.5$ & 212.5 & 48.4 & 124.4 & 22.8 & 46.3 & 2.65 & 2.85 & 2.72 \\
\hline PACl $1.5+50 \mathrm{mg} / \mathrm{L}$ LPF & 233.2 & 68.4 & 144.6 & 29.3 & 46.2 & 2.58 & 2.80 & 2.69 \\
\hline$\left(\mathrm{PACl}+\mathrm{SIP}_{100 \mathrm{mg} / \mathrm{L}}\right) 1.5$ & 133.9 & 44.6 & 64.2 & 33.3 & 21.9 & 2.61 & 2.88 & 2.79 \\
\hline PACl $1.5+100 \mathrm{mg} / \mathrm{L}$ SIP & 248.6 & 52.4 & 130.5 & 21.1 & 39.8 & 2.66 & 2.88 & 2.75 \\
\hline
\end{tabular}

rearrangement of residual $\mathrm{Al}$ species-magnetic nanoparticle clusters after breakage might occur, possibly hindering Al species interacting with the kaolin surface and reducing its ability to form bridges between particles. Therefore, all the MC-flocs generally showed the poorer recovery ability than the MSC-flocs. As denoted in Section 3.1, the LPF particles used in this work were superparamagnetic. If the external magnetic field is removed after the magnetic sedimentation, no magnetic attraction between particles will exist anymore. The weak LPF-involved MC-flocs may be easily destroyed by physical agitation whereas they are hard to re- 
form. Hence, the separated magnetic seeds can be collected and recovered via re-placing the broken flocs in the magnetic field.

\subsection{Proposed mechanisms of MC and MSC}

Based on the above discussion, MC and MSC performed differently in the coagulation-magnetic separation process. Plausible mechanisms of MPACl1.5 formation and coagulationsedimentation of MC and MSC are schematically established herein.

As illustrated in Fig. 8(a), Al species-nanoparticle clusters were formed when magnetic nanoparticles as added into PACl1.5 solutions and the proportion of $\mathrm{Al}_{\mathrm{un}}$ was correspondingly increased. In that case, the magnetic component would sufficiently mix with coagulant and well participate in coagulation, forming flocs that were smaller and more compact due to the magnetic attraction between magnetic nanoparticles inside flocs. The flocs could easily precipitate in the presence of external magnetic field. However, when seeding magnetic nanoparticles directly into the target water (Fig. 8(b)), the traditional PACl-kaolin-HA flocs were apt to form. A part of magnetic nanoparticles would be wrapped into those flocs by particle collision and PACl coagulation. However, there would also be a small part of free magnetic particles which were not involved in the floc formation and finally separated by magnetic separation (called "ineffective magnetic seeds"). In that case, MSC-flocs would have lower sedimentation efficiency than MC-flocs.

Last but not least, the preparation and application of magnetic coagulants is promising with respect to greatly reducing the magnetic component dosage and thereby the cost of magnetic coagulation technique. On seeding magnetic components into wastewaters, the mass ratio of magnetic powder to coagulant was from 10,67 to 100 , or even higher [16,43]; for the application of magnetic coagulants, that ratio could be reduced to approximately $1.5-2.5$ [21-23].

\section{Conclusions}

In the present work, the ferromagnetic nanoparticles seeded PACls were prepared as magnetic coagulants; their coagulationmagnetic sedimentation behaviors were then particularly compared with the magnetic seeding coagulation in an external magnetic field of $2 \mathrm{~T}$. The superparamagnetic LPF and paramagnetic SIP significantly influenced the Al species, the morphology as well as the size of Al species. By adding LPF and SIP, the content of largesize $\left[\mathrm{Al}_{\mathrm{un}}\right]$ in $\mathrm{MPACl}$ increased. The formation of "Al speciesnanoparticle clusters" led to the colloidal configuration of MPACl.

In the external magnetic field, the MPACl-involved magnetic separation could result in a lower residual turbidity and a higher magnetic sedimentation efficiency compared with the magnetic seeding coagulation. The MPACl exhibited a high organic matter removal efficiency compared with $\mathrm{PACl}$ alone. MC-flocs were smaller, weaker and less reversible than MSC-flocs. Particularly, the weak LPF-involved MC-flocs may be easily destroyed by physical agitation whereas they are hard to re-form. Those separated magnetic seeds are highly possible to be recovered via re-placing the broken flocs in the magnetic field. Considering the coagulationseparation performance and floc properties, $\left(\mathrm{PACl}+\mathrm{LPF}_{50 \mathrm{mg} / \mathrm{L}}\right) 1.5$ should be favored by the practical application. The MCseparation was superior to the MSC-separation process because of the much lower demand of magnetic particles and the better settleability.

\section{Acknowledgements}

This research was funded by the following foundations: National Natural Science Foundation of China (No. 51608373,
51378014, 51338008, 51338010, 21107125), 59th China Postdoctoral Science Foundation (No. 2016M591713), and Foundation of State Key Laboratory of Pollution Control and Resource Reuse (Tongji University), China, (No. CRRY15001). The authors are very grateful to the technical support from the Research Center for Eco-Environmental Sciences, Chinese Academy of Sciences.

\section{Appendix A. Supplementary material}

Supplementary data associated with this article can be found, in the online version, at http://dx.doi.org/10.1016/j.seppur.2017.03. 028 .

\section{References}

[1] A. Matilainen, M. Vepsäläinen, M. Sillanpää, Natural organic matter removal by coagulation during drinking water treatment: a review, Adv. Colloid Interface Sci. 159 (2010) 189-197.

[2] J. Gasperi, B. Laborie, V. Rocher, Treatment of combined sewer overflows by ballasted flocculation: removal study of a large broad spectrum of pollutants, Chem. Eng. J. 211-212 (2012) 293-301.

[3] R.D. Ambashta, M. Sillanpää, Water purification using magnetic assistance: review, J. Hazard. Mater. 180 (2010) 38-49.

[4] S.C.N. Tang, I.M.C. Lo, Magnetic nanoparticles: essential factors for sustainable environmental applications, Water Res. 47 (2013) 2613-2632.

[5] C.-F. Chang, P.-H. Lin, W. Höll, Aluminum-type superparamagnetic adsorbents: synthesis and application on fluoride removal, Colloids Surf. Physicochem. Eng. Asp. 280 (2006) 194-202.

[6] A. Hatamie, H. Parham, B. Zargar, Z. Heidari, Evaluating magnetic nanoferrofluid as a novel coagulant for surface water treatment, J. Mol. Liq. 219 (2016) 694-702.

[7] T. Wang, W.-L. Yang, Y. Hong, Y.-L. Hou, Magnetic nanoparticles grafted with amino-riched dendrimer as magnetic flocculant for efficient harvesting of oleaginous microalgae, Chem. Eng. J. 297 (2016) 304-314.

[8] Y. Chen, M. Luo, W. Cai, Influence of operating parameters on the performance of magnetic seeding flocculation, Environ. Sci. Pollut. Res. 23 (2016) 28732881.

[9] Z. Ai, Y. Cheng, L. Zhang, J. Qiu, Efficient removal of $\mathrm{Cr}(\mathrm{VI})$ from aqueous solution with Fe@Fe2O3 core-shell nanowires, Environ. Sci. Technol. 42 (2008) 6955-6960.

[10] X. Hu, Y. Liu, H. Wang, A. Chen, G. Zeng, S. Liu, Y. Guo, X. Hu, T. Li, Y. Wang, L. Zhou, S. Liu, Removal of $\mathrm{Cu}(\mathrm{II})$ ions from aqueous solution using sulfonated magnetic graphene oxide composite, Sep. Purif. Technol. 108 (2013) 189-195.

[11] N. Kondo, K. Yokoyama, S. Hosaka, Magnetic separation of organic dyes in wastewater using superconducting bulk magnets, Key Eng. Mater. 534 (2013) 99-103.

[12] S. Relle, S.B. Grant, One-step process for particle separation by magnetic seeding, Langmuir 14 (1998) 2316-2328.

[13] I.C. Mac Rae, Removal of pesticides in water by microbial cells adsorbed to magnetite, Water Res. 19 (1985) 825-830.

[14] R. Gregory, R.J. Maloney, M. Stockley, Water treatment using magnetite: a study of a sirofloc pilot plant, Water Environ. J. 2 (1988) 532-544.

[15] A. Waters, Process experience with the Sirofloc demonstration plant, Filtr. Sep. 28 (1991) 15.

[16] T.-J. Wan, S.-M. Shen, S.-H. Siao, C.-F. Huang, C.-Y. Cheng, Using magnetic seeds to improve the aggregation and precipitation of nanoparticles from backside grinding wastewater, Water Res. 45 (2011) 6301-6307.

[17] C.-J.M. Chin, P.-W. Chen, L.-J. Wang, Removal of nanoparticles from CMP wastewater by magnetic seeding aggregation, Chemosphere 63 (2006) 18091813.

[18] F. Sakaguchi, F. Mishima, Y. Akiyama, S. Nishijima, Fundamental study on magnetic separation of aquatic organisms using a superconducting magnet, IEEE Trans. Appl. Supercond. 20 (2010) 969-972.

[19] J. Lohwacharin, A. Phetrak, K. Oguma, S. Takizawa, Flocculation performance of magnetic particles with high-turbidity surface water, Water Sci. Technol.Water Supply 14 (2014) 609-617.

[20] K. Simeonidis, E. Kaprara, T. Samaras, M. Angelakeris, N. Pliatsikas, G. Vourlias, M. Mitrakas, N. Andritsos, Optimizing magnetic nanoparticles for drinking water technology: the case of $\mathrm{Cr}(\mathrm{VI})$, Sci. Total Environ. 535 (2015) 61-68.

[21] D. Liu, F. Li, B. Zhang, Removal of algal blooms in freshwater using magnetic polymer, Water Sci. Technol. 59 (2009) 1085-1091.

[22] D. Liu, P. Wang, G. Wei, W. Dong, F. Hui, Removal of algal blooms from freshwater by the coagulation-magnetic separation method, Environ. Sci. Pollut. Res. 20 (2013) 60-65.

[23] M. Zhang, F. Xiao, X.Z. Xu, D.S. Wang, Novel ferromagnetic nanoparticle composited PACls and their coagulation characteristics, Water Res. 46 (2012) $127-135$.

[24] B. Liu, B. Gao, X. Xu, W. Hong, Q. Yue, Y. Wang, Y. Su, The combined use of magnetic field and iron-based complex in advanced treatment of pulp and paper wastewater, Chem. Eng. J. 178 (2011) 232-238. 
[25] J. Wang, J. Yang, H. Zhang, W. Guo, H.-H. Ngo, Feasibility study on magnetic enhanced flocculation for mitigating membrane fouling, J. Ind. Eng. Chem. 26 (2015) 37-45

[26] C.S. Uyguner, S.A. Suphandag, A. Kerc, M. Bekbolet, Evaluation of adsorption and coagulation characteristics of humic acids preceded by alternative advanced oxidation techniques, Desalination 210 (2007) 183-193.

[27] H. Liu, C. Hu, H. Zhao, J. Qu, Coagulation of humic acid by PACl with high content of Al13: The role of aluminum speciation, Sep. Purif. Technol. 70 (2009) 225-230.

[28] E. Illés, E. Tombácz, The role of variable surface charge and surface complexation in the adsorption of humic acid on magnetite, Colloids Surf. Physicochem. Eng. Asp. 230 (2003) 99-109.

[29] E. Illés, E. Tombácz, The effect of humic acid adsorption on pH-dependent surface charging and aggregation of magnetite nanoparticles, J. Colloid Interface Sci. 295 (2006) 115-123.

[30] A. Hajdú, E. Illés, E. Tombácz, I. Borbáth, Surface charging, polyanionic coating and colloid stability of magnetite nanoparticles, Colloids Surf. Physicochem. Eng. Asp. 347 (2009) 104-108.

[31] K. Yang, D. Lin, B. Xing, Interactions of humic acid with nanosized inorganic oxides, Langmuir 25 (2009) 3571-3576.

[32] R.-Y. Hong, J.-H. Li, S.-Z. Zhang, H.-Z. Li, Y. Zheng, J. Ding, D.-G. Wei, Preparation and characterization of silica-coated Fe304 nanoparticles used as precursor of ferrofluids, Appl. Surf. Sci. 255 (2009) 3485-3492.

[33] Y. Xu, D. Wang, H. Liu, L. Yiqiang, H. Tang, Optimization of the separation and purification of Al13, Colloids Surf. Physicochem. Eng. Asp. 231 (2003) 1-9.

[34] X. Ge, Y. Zhou, C. Lü, H. Tang, AFM study on the adsorption and aggregation behavior of dissolved humic substances on mica, Sci. China Ser. B 49 (2006) 256-266.
[35] Y. Wang, B.-Y. Gao, X.-M. Xu, W.-Y. Xu, G.-Y. Xu, Characterization of floc size, strength and structure in various aluminum coagulants treatment, J. Colloid Interface Sci. 332 (2009) 354-359.

[36] P. Jarvis, B. Jefferson, S.A. Parsons, Breakage, regrowth, and fractal nature of natural organic matter flocs, Environ. Sci. Technol. 39 (2005) 2307-2314.

[37] J. Deng, C. He, Y. Peng, J. Wang, X. Long, P. Li, A.S.C. Chan, Magnetic and conductive $\mathrm{Fe}_{3} \mathrm{O}_{4}$-polyaniline nanoparticles with core-shell structure, Synth. Met. 139 (2003) 295-301.

[38] R.Y. Hong, Preparation and application of magnetic nanoparticles and fluid, China, 2008.

[39] S. Sun, H. Zeng, D.B. Robinson, S. Raoux, P.M. Rice, S.X. Wang, G. Li, Monodisperse MFe2O4 (M = Fe Co, Mn) nanoparticles, J. Am. Chem. Soc. 126 (2003) 273-279.

[40] A.-F. Ngomsik, A. Bee, M. Draye, G. Cote, V. Cabuil, Magnetic nano- and microparticles for metal removal and environmental applications: a review, Comptes Rendus Chim. 8 (2005) 963-970.

[41] M.A. Yukselen, J. Gregory, The reversibility of floc breakage, Int. J. Miner. Process. 73 (2004) 251-259.

[42] Z. Zhu, T. Li, J. Lu, D. Wang, C. Yao, Characterization of kaolin flocs formed by polyacrylamide as flocculation aids, Int. J. Miner. Process. 91 (2009) 94-99.

[43] C. Wen-song, L. Hua-shi, Z. Shuo-feng, Study on treatment of printing and dyeing wastewater by magnetic seed coagulation-high gradient magnetic separation, in: International Conference on Green Building, Materials and Civil Engineering (GBMCE 2011), Shangri La, P.R. China, 2011. 